Available online at http://journal.stkip-andi-matappa.ac.id/index.php/histogram/index

Histogram: Jurnal Pendidikan Matematika 4(2)., 2020, 500 - 517

\title{
PENELITIAN DAN PENGEMBANGAN KONTEN LMS GOOGLE CLASSROOM MATA KULIAH GEOMETRI UNTUK CALON GURU MATEMATIKA
}

\author{
Deshinta Puspa Ayu Dwi Argaswari ${ }^{*}$ \\ ${ }^{1}$ Universitas Sampoerna \\ * Corresponding Author. Email: deargaswari@gmail.com \\ Received: 27 Agsustus 2020; Revised: 15 September 2020 ; Accepted: 30 September 2020
}

\begin{abstract}
ABSTRAK
Penelitian bertujuan untuk mengetahui proses, hasil, dan kualitas dari LMS Google Classroom pada pembelajaran Geometri dengan metode Blended Learning yang sesuai dengan kebutuhan calon guru matematika. Untuk mengetahui proses dan hasil, penelitian dan pengembangan konten dilakukan mengikuti tahapan penelitian dan pengembangan Plomp. Kemudian kualitas hasil LMS dievaluasi menggunakan standar MTebe dan Raisamo yang terdiri dari aspek kualitas mata kuliah, kualitas sistem, penggunaan LMS, kepuasan pengguna, dan kebermanfaatan. Metode penelitian dan pengembangan terdiri dari invesigasi awal, desain, realisasi, tes-evaluasirevisi, dan implementasi. Hasil dari penelitian dan pengembangan ini adalah sebuah LMS Google Classroom yang telah lengkap dengan konten Geometry. Konten telah divalidasi oleh ahli dan diujicobakan pada subyek bukan sampel. Setelah itu, LMS diimplementasikan dan diperoleh hasil yang menunjukkan evaluasi terhadap kualitas LMS. Evaluasi menunjukkan kualitas aspek mata kuliah bernilai 3.66 dari 4, kualitas sistem 3.72 dari 4, kualitas kepuasan pengguna 3.16 dari 4, kualitas pengunaan LMS 3.29 dari 4, dan kualitas kebermanfaat 3 dari 4. Kata Kunci: LMS, Geometri, Google Classroom
\end{abstract}

\section{ABSTRACT}

The aims of this research to know and describe the process, result, and quality of the LMS Google Classroom in geometry course for the blended learning model which is appropriate for mathematics teacher candidates' needs. To answer the process and result of LMS, the research and development followed the $R \& D$ steps of Plomp. After that, the quality of the LMS is evaluated using the MTebe \& Raisamo standard which consists of these aspects: course quality, system quality, learner satisfaction, LMS use, and perceived benefits. The R\&D methods consist of these steps: initial investigation, design, realization, test-evaluation-revision, and implementation. The result of this $R \& D$ is a complete form of LMS Google Classroom for Geometry Course. The content is validated by experts and is tested into teaching and learning geometry for non-sample or non-participants. After that, the LMS is implemented in the Geometry course and the quality is being evaluated. The evaluation result shows that the course quality got a score of 3.66 out of 4, system quality scored 3.72 out of 4 , user satisfaction scored 3.16 out of 4 , user quality scored 3.28 out of 4 , and benefit quality scored 3 out of 4 .

Keywords: LMS, Geometry, Google Classroom

How to Cite: Argaswari, D, P, A, D. (2020). Penelitian Dan Pengembangan Konten Lms Google Classroom Mata Kuliah Geometri Untuk Calon Guru Matematika . Histogram: Jurnal Pendidikan Matematika, 4(2), 500 - 517, doi: http://dx.doi.org/10.31100/histogram.v4i2.754

Permalink/DOI: http://dx.doi.org/10.31100/histogram.v4i2.754

\section{PENDAHULUAN}

Teknologi digital adalah teknologi pembelajaran yang memiliki peran penting dalam pembelajaran dan pelatihan di era modern saat ini (Ventayen et al., 2018). Selain itu mahasiswa yang tengah menempuh Pendidikan untuk menjadi calon guru matematika di

Prodi Pendidikan Matematika Fakultas Pendidikan Universitas Sampoerna merupakan

Copyright $\subset$ 2020, THE AUTHOR (S). This article distributed under the CC-BY-SA-license. 


\section{Histogram: Jurnal Pendidikan Matematika, 4 (2), 2020 - 501 \\ Deshinta Puspa Ayu Dwi Argaswari ${ }^{1}$}

milenial yang nantinya akan mengajar matematika untuk milenial juga, sehingga cukup tergantung pada penggunaan teknologi digital. Kebutuhan tersebut disadari oleh Prodi Pendidikan Matematika, sehingga system pembelajaran tiap-tiap mata kuliah dianjurkan menggunakan sistem "blended learning" yaitu kegiatan belajar mengajar yang tidak hanya terdiri dari pembelajaran secara tatap muka namun juga pembelajaran secara daring atau online.

Kebutuhan pembelajaran secara daring ini juga telah dibahas dalam penelitian pada dekade ini. Darmawan (2012) menyatakan bahwa sebaiknya penggunaan teknologi informatika sudah mulai diperkenalkan dan digunakan pada lembaga-lembaga pendidikan. Selain itu Nasrulloh dan Ismail (2018) dalam penelitiannya menyebutkan bahwa terdapat $77,6 \%$ guru yang menggunakan metode pengajaran konvensional padahal $85,1 \%$ siswa menyatakan lebih menyetujui pembelajaran dilakukan dengan memanfaatkan teknologi. Pemanfaatan teknologi dapat dirancang pada sebuah sistem e-learning yang dapat memudahkan siswa untuk mengakses informasi, sistem tersebut dikenal dengan Learning Management System (LMS) (Retnani, 2011).

Desain pembelajaran online dilakukan dengan menggunakan Learning Management System (LMS). LMS merupakan sebuah system berbasis internet yang disajikan dalam bentuk website. LMS digunakan sebagai keperluan administrasi akademik yaitu mengelola material pembelajaran, tugas hingga ujian atau kuis. Sistem ini memiliki kapasitas untuk membuat lingkungan belajar virtual bahkan universitas virtual yang pembelajarannya sepenuhnya dilakukan secara online (Coates et al., 2005). Meskipun penggunaan LMS untuk kelas yang sepenuhnya online masih diperdebatkan dalam hal isu pedagogik, akan tetapi penggunaan LMS pada dekade ini mengalami perkembangan yang cepat dan memenuhi kebutuhan pembelajaran. Pengembangan LMS untuk kegiatan belajar mengajar tidak diatur secara baku, akan tetapi terdapat standar intenasional LMS yang mengatur aspek-aspek berikut agar tersedia di LMS yaitu: 1) Laman komunikasi yang digunakan untuk pengumuman informasi, chat, posting, dan diskusi kelas, 2) Pengembangan konten yang berisi material-material pembelajaran baik yang diupload maupun berupa link dan lain sebagainya. 3) Assessmen formatif dan sumatif yang berisi berbagai laman untuk tes, mengumpulkan tugas individu maupun kolaborasi kelompok, serta memberikan balikan atau feedback, 4) Management kelas dan pengguna yang digunakan untuk registrasi, menampilkan jadwal, serta mengatur aktivitas siswa. 


\section{Histogram: Jurnal Pendidikan Matematika, 4 (2), 2020 - 502 \\ Deshinta Puspa Ayu Dwi Argaswari ${ }^{1}$}

LMS dipilih karenan dapat menyusun kesatuan dari mata kuliah dalam satu website dan lebih efektif untuk proses pembelajaran sehingga dapat mencapai tujuan pembelajaran dengan lebih baik daripada menggunakan media social yang memiliki banyak gangguan dan selingan (Mayes, 2004). Dengan menggunakan LMS, Pendidikan dapat terjadi kapan saja dan dimana saja. Oleh karenanya dosen diharapkan dapat mengembangkan pembelajaran menggunakan LMS. Peneliti memilih menggunakan LMS Google Classroom dikarenakan tidak memerlukan biaya dalam penggunaannya.

Mata kuliah yang dikembangkan menggunakan LMS Google Classroom adalah mata kuliah Geometri. Hal ini dikarenakan masih belum tersedianya LMS Google Classroom maupun LMS lain yang mengembangkan mata kuliah Geometri yang digunakan untuk mengajar para calon guru.

Tujuan pembelajaran geometri untuk calon guru sedikit berbeda dengan tujuan belajar geometri di sekolah menengah maupun tujuan belajar geometri di program studi matematika murni maupun terapan. Mata kuliah geometri untuk calon guru matematika tidak hanya bertujuan agar calon guru menguasai konten geometri akan tetapi juga mendorong refleksi pemahaman konsep terhadap desain pembelajaran yang akan disusun oleh calon guru dikemudian hari.

LMS Google Classroom untuk mata kuliah Geometri ini dinilai menggunakan standar evaluasi LMS oleh MTebe \& Raisamo (2014) yang disesuaikan dengan kebutuhan evaluasi penelitian dan pengembangan ini. Pada standar evaluasi ini, terdapat aspek kualitas mata kuliah, kualitas sistem, kualitas servis, kepuasan pengguna, penggunaan LMS, dan kebermanfaatan. Penilaian ini akan menjelaskan sejauh mana kegunaan LMS Google Classroom yang telah dikembangkan berdasarkan hasil penelitian dan pengembangan. Permasalahan dalam penelitian dan pengembangan ini adalah 1) bagaimana proses dan hasil penelitian dan pengembangan LMS Google Classroom dalam mata kuliah Geometri yang dikembangkan sesuai dengan kebutuhan calon guru, 2) bagaimana kualitas Google Classroom Mata Kuliah Geometri

Penelitian ini memiliki tujuan untuk meneliti dan mengembangkan sarana pembelajaran LMS Google Classroom untuk mata kuliah geometri dan melakukan evaluasi LMS Google Classroom Geometri yang telah dikembangkan. LMS Google Classroom Geometri ini diharapkan dapat dijadikan sarana belajar bagi calon guru matematika sehingga dapat lebih menguasai konsep-konsep geometri yang nanti akan diajarkan ketika menjadi guru 


\section{METODE PENELITIAN}

\section{A. Tempat dan Waktu}

Penelitian dan pengembangan ini dilaksanakan pada kurung 2 semester dimulai dari bulan Agustus 2019 untuk merancang desain, evaluasi, revisi, dan ujicoba awal kepada subjek non-sampel. Kemudian LMS diimplementasikan dengan mengambil populasi calon guru matematika di Prodi Pendidikan Matematika, Fakultas Pendidikan, Univeritas Sampoerna. Partisipan terdiri dari partisipan uji coba yaitu mahasiswa calon guru matematika yang akan mengambil mata kuliah Geometri pada Semester Genap TA 2019/2020 berjumlah 6 orang.

Metode yang digunakan adalah metode penelitian dan pengembangan (Research dan Development). Metode penelitian dan pengembangan adalah metode yang dilakukan untuk menyempurnakan produk yang sudah ada maupun mengembangkan produk baru yang dapat dipertanggungjawabkan baik berupa program perangkat lunak, model Pendidikan, maupun perangkat pembelajaran (Argaswari, 2018).

\section{B. Tahap pelaksanaan /Rancangan Penelitian}

Penelitian dan pengembangan dapat dilakukan dengan menggunakan 10 langkah penelitian dan pengembangan oleh Plomp (Heryaningsih \& Usodo, 2015). Berikut adalah penjelasan langkah penelitian dan pengembangan:

1. Tahap Investigasi awal (Preliminary Investigation)

Pada tahap ini ini dilakukan analisis terhadap permasalahan penelitian dengan memperhatikan analysis informasi, konteks, identifikasi masalah, dan perencanaan kegiatan lanjutan. Peneliti mengumpulkan informasi mengenai kondisi produk LMS Geometri yang sudah ada serta tanggapan calon guru mengenai LMS Geometri yang diharapkan dan dibutuhkan. Selain itu, peneliti juga melakukan studi literatur terhadap LMS Geometri.

2. Tahap Desain (Design)

Dengan mengacu pada hasil pada tahap investigasi awal, tahap selanjutnya dilakukan perencanaan desain LMS yang akan menjawab permasalahan serta identifikasi kebutuhan pada tahap sebelumnya.

3. Tahap Realisasi (Realization) 


\section{Histogram: Jurnal Pendidikan Matematika, 4 (2), 2020 - 504}

Deshinta Puspa Ayu Dwi Argaswari ${ }^{1}$

Pada tahap ini desain yang telah dirancang pada tahap desain kemudian direalisasikan dalam bentuk produk nyata. Produk yang dimaksudkan dalam penelitian ini adalah LMS. Sehingga hasil dari tahap ini berupa draf produk LMS yang sesuai dengan desain dan masalah pada tahap-tahap sebelumnya

4. Tahap Tes, Evaluasi, dan Revisi

Tahap ini merupakan siklus revisi terhadap draf produk LMS yang telah dirancang. LMS yang telah dikembangkan diujicobakan pengunaannya dengan melibatkan beberapa ahli. Diskusi terfokus kemudian akan digunakan sebagai evaluasi terhadap LMS, dan selanjutnya hasil evaluasi memberikan balikan untuk perbaikan LMS.

5. Implementasi dan Diseminasi

Pada tahap ini, hasil draf produk LMS yang telah direvisi kemudikan diimplementasikan dalam pembelajaran dikelas. Hasilnya kemudian dievaluasi menggunakan standar evaluasi LMS oleh Mtebe dan Raisoma. Diseminasi kemudian dilakukan dengan menyebarkan luaskan hasil penelitian dalam bentuk jurnal.

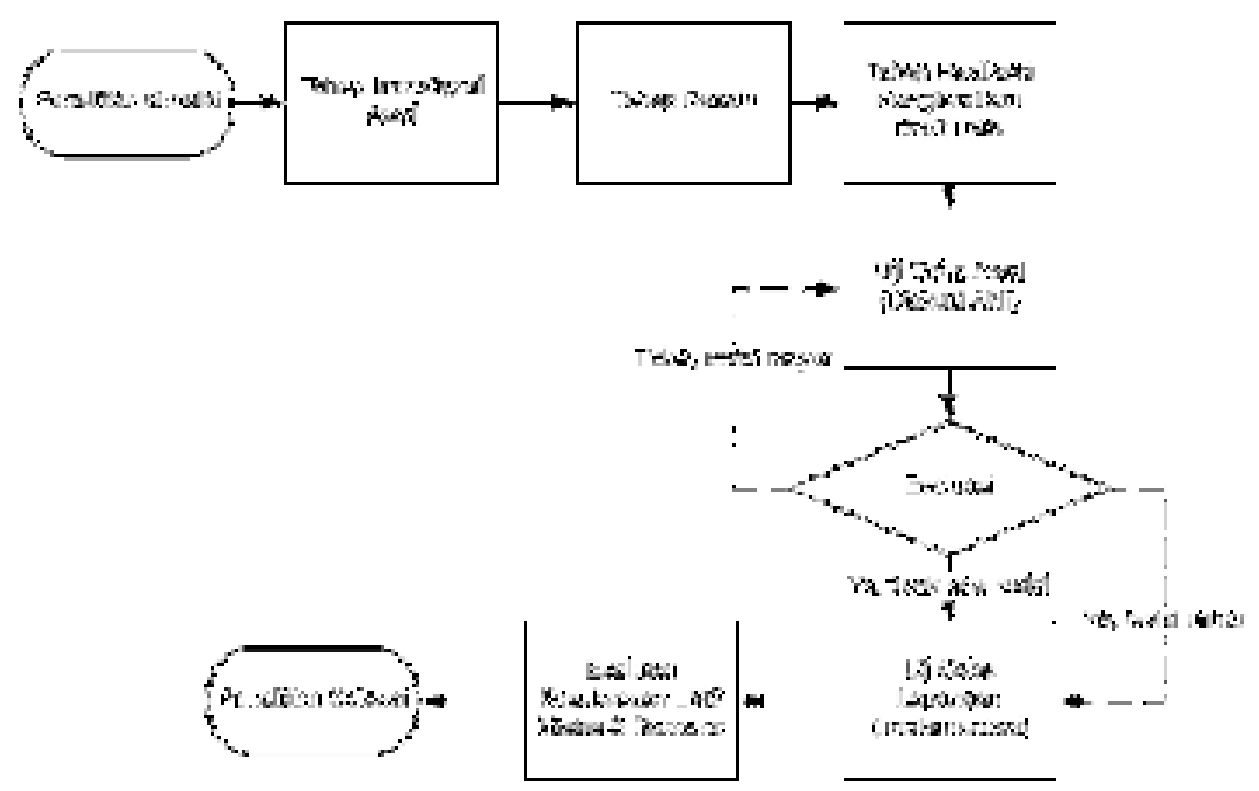

Gambar 1. Diagram alir penelitian dan pengembangan

Terdapat dua metode penelitian dalam penelitian dan pengembangan yaitu metode desktiptif, dan metode evaluatif (Sukmadinata, 2005). Metode deskriptif dalam penelitian ini akan memaparkan kondisi produk yang sudah ada serta kondisi pengguna, sebagai tambahan juga akan dipaparkan mengenai produk yang diharapkan dan dibutuhkan 


\section{Histogram: Jurnal Pendidikan Matematika, 4 (2), 2020 - 505 \\ Deshinta Puspa Ayu Dwi Argaswari ${ }^{1}$}

pengguna. Metode evaluasi akan memaparkan proses evaluasi mengenai pengembangan produk. Evaluasi dilakukan dengan memperhatikan masukan serta saran untuk penyempurnaan produk dari ahli serta melihat tanggapan calon guru terhadap LMS sesuai dengan standar evaluasi Mtebe \& Raisoma.

\section{HASIL DAN PEMBAHASAN}

\section{A. Hasil Penelitian}

Berdasarkan penelitian dan pengembangan yang telah dilakukan, diperoleh sebuah produk LMS Google Classroom Mata Kuliah Geometry dengan proses pengembangan sebagai berikut.

1. Tahap Investigasi Awal

Peneliti mengumpulkan data mengenai kebutuhan calon guru akan LMS Google Classroom. Berdasarkan wawancara dan diskusi, mahasiswa menyatakan perlu agar seluruh materi tersedia di LMS serta material tambahan berupa video pembelajaran ataupun link untuk belajar selain dari penjelasan yang diberikan dikelas.

2. Tahap Desain

Dengan mempertimbangkan hasil dari tahap sebelumnya, pengembangan LMS Google Classroom dirancang agar memenuhi kebutuhan mahasiswa yaitu LMS yang komprehensif menyediakan seluruh material pembelajaran secara runut sesuai dengan pertemuan yang dilakukan pada perkuliahan tatap muka. Oleh karenanya, desain LMS dibedakan berdasarkan topik pertemuan pada masing-masing minggu dan didahului dengan kontrak kuliah.

3. Tahap Realisasi

Pengembangan draf LMS Google Classroom untuk mata kuliah Geometry mengikuti panduan dari pengembangan LMS dengan tetap memperhatikan kebutuhan mahasiswa. Pengembangan LMS untuk kegiatan belajar mengajar tidak diatur secara baku, akan tetapi terdapat standar intenasional LMS yang mengatur beberapa aspek-aspek agar tersedia di LMS (Bersin, 2003). Berikut adalah detil pengembangan LMS Google Classroom untuk perkuliahan Geometry bagi para calon guru matematika.

a. Laman komunikasi yang digunakan untuk pengumuman informasi, chat, posting, dan diskusi kelas.

Laman komunikasi pada LMS yang dikembangkan tersedia pada menu "stream". Tampilan stream adalah tampilan yang paling awal muncul ketika mahasiswa mengakses 


\section{Histogram: Jurnal Pendidikan Matematika, 4 (2), 2020 - 506 \\ Deshinta Puspa Ayu Dwi Argaswari ${ }^{1}$}

LMS. Menu ini digunakan oleh dosen untuk membuat pengumuman terkait perkuliahan seperti diskusi persiapan tugas, materi ujian, dan keperluan kelas. Pada laman ini mahasiswa dapat bertanya serta memberikan informasi. Contoh dibawah ini adalah diskusi mengenai persiapan ujian akhir. Dosen menanyakan apabila siswa membutuhkan sesi tambahan, mahasiswa akan merespon. Apabila sesi tidak dapat dilakukan secara online, maka sesi dilakukan secara tatap muka sesuai janji.

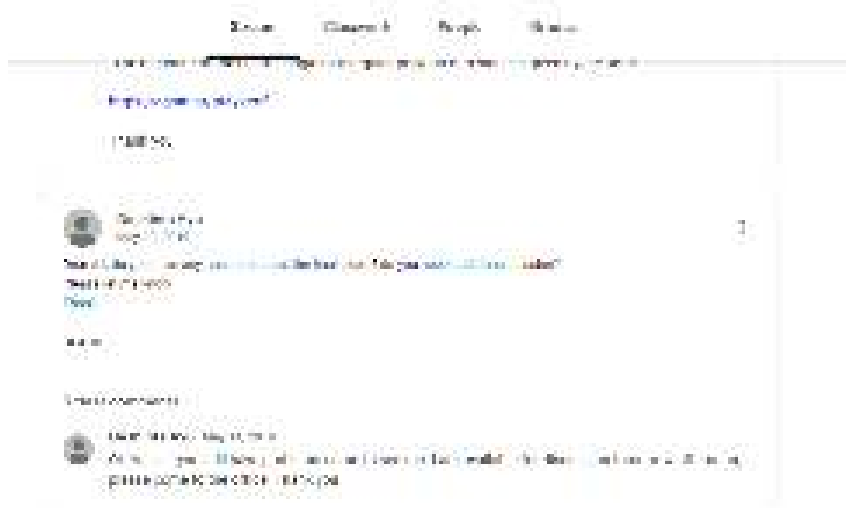

Gambar 2. Laman Komunikasi

b. Pengembangan konten yang berisi material-material pembelajaran baik yang diupload maupun berupa link dan lain sebagainya

Konten pembelajaran yang berisi materi-materi perkuliahan juga disajikan pada LMS Google Classroom secara runut. Konten disajikan urut sesuai dengan materi yang dibahas. Pada perkuliahan Geometry terdapat 16 sesi pertemuan dengan masing-masing sesi berdurasi 250 menit yang digunakan untuk mempelajari 10 bab Geometri. Pada laman LMS Google Classroom konten disajikan pada bagian "Classwork". Bab-bab pada classwork dibagi menjadi 13 bab. Satu bab diawal disebut sesi "Course Contract" digunakan untuk menunjukkan silabus dan peraturan kuliah yang akan ditaati mahasiswa dalam satu semester. Kemudian sebelum masuk pada materi geometri, mahasiswa diajak untuk mengenal bidang studi geometri melalui bab "Introduction to Geometry" yang membahas Geometri Euclid dan Teori Belajar Geometri Van Hiele. 10 Bab selanjutnya membahas materi-materi geometri yang berisi buku Elementary Geometry for College Students oleh Alexander dan Koberlain, aktivitas kelas, material tambahan, serta laman pengumpulan tugas.

- Kegiatan apresepsi diberikan dengan membawa siswa melihat bentuk-bentuk bangunan yang menggunakan prinsip-prinsip topik geometri yang akan dipelajari. Pada gambar 2 
merupakan salah satu contoh kegiatan apresepsi. Kegiatan dilakukan dengan membawa siswa menjelajah secara online ke sebuah bangunan yang menggunakan prinsip garus sejajar yaitu Bunker Hill Bridge. Mahasiswa akan menjelajah menggunakan Google Earth, dan kemudian menuliskan refleksi dengan menjawab pertanyaan terbimbing.

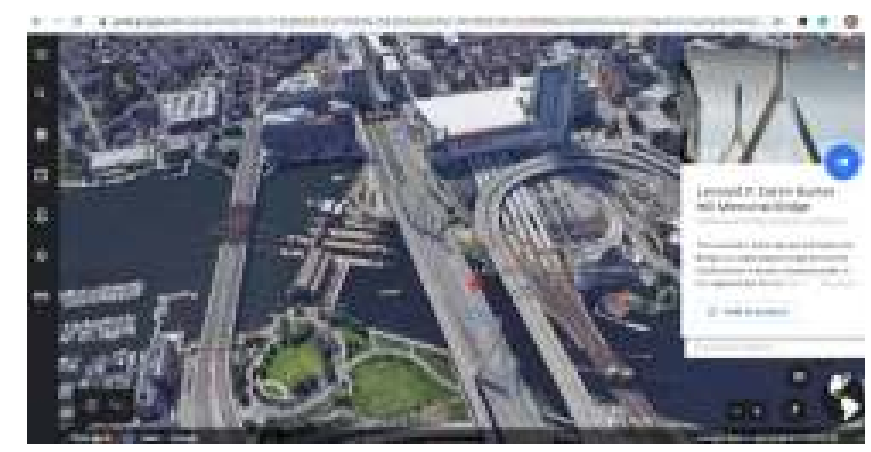

Gambar 3. Kegiatan Apersepsi

- Kegiatan kelas diberikan dengan memberikan mahasiswa kesempatan untuk mengeksplorasi pembuktian geometri. Seperti telah dijelaskan pada Latar Belakang bahwa pembelajaran dilakukan dengan cara blended learning yaitu kombinasi pembelajaran online dan pembelajaran tatap muka. Kegiatan kelas dilakukan untuk memfasilitasi kegiatan tatap muka, hasil dari kegiatan kemudian didiskusikan dalam diskusi kelas. Selanjutnya mahasiswa diminta untuk mengunggah hasil dari pekerjaan. Hal ini berfungsi agar mahasiswa dan dosen dapat menyimpan dokumen sebagai bukti dari kegiatan perkuliahan.

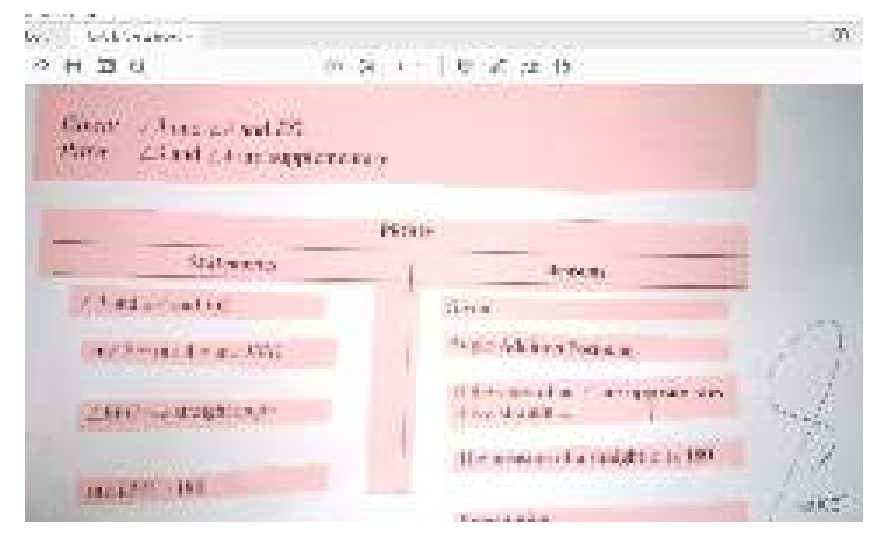

Gambar 4. Diskusi Luring

- Tugas-tugas diberikan pada setiap topik perkuliahan. Tugas dan instruksi tugas sudah disiapkan pada LMS Google Classroom, sehingga pada saat sesi tatap muka, dosen bisa langsung merujuk pada tugas yang tertulis di LMS. Selanjutnya mahasiswa mengumpulkan tugas pada laman yang sudah disediakan di LMS. Hal ini memudahkan 


\section{Histogram: Jurnal Pendidikan Matematika, 4 (2), 2020 - 508 \\ Deshinta Puspa Ayu Dwi Argaswari ${ }^{1}$}

baik dosen maupun mahasiswa karena kedua pihak akan memiliki dokumen dari tugas yang diberikan. Selain itu, dosen memberikan komentar dan nilai pada LMS sehingga siswa akan mengetahui komentar dan nilai mereka secara real time.

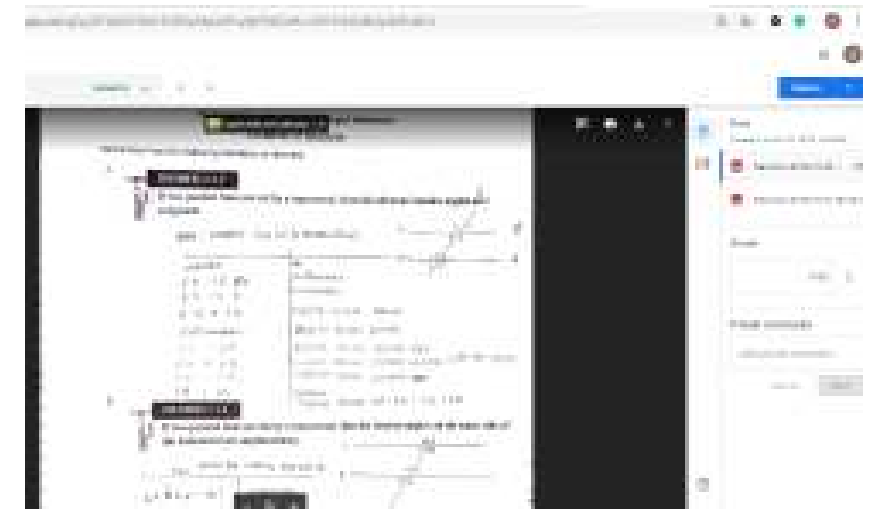

Gambar 5. Pengumpulan Tugas

c. Assessmen formatif dan sumatif

Terdapat assessmen pada LMS yang berisi berbagai laman untuk tes, mengumpulkan tugas individu maupun kolaborasi kelompok, serta memberikan balikan

d. Manajemen kelas dan pengguna

Manajemen kelas dan pengguna pada LMS digunakan untuk registrasi, menampilkan jadwal, serta mengatur aktivitas siswa.

4. Tahap Tes, Evaluasi, dan Revisi

LMS yang telah selesai dikembangkan kemudian diujikan kepada ahli dan partisipan uji coba. Validasi ahli dilakukan kepada 3 ahli pembelajaran matematika yaitu 1 dosen, dan 2 guru matematika yang telah menggunakan LMS Google Classroom. Aspek yang divalidasi terdiri dari aspek kelayakan isi (keakuratan materi dan kemutakhiran materi, aspek kelayakan penyajian (Teknik penyajian, penyajian LMS, kelengkapan), dan aspek kelayakan Bahasa dan keterbacaan (kesesuaian dengan tingkat perkembangan peserta didik dan kesesuaian dengan Kaidah Bahasa yang benar). Berdasarkan validasi yang dilakukan, terdapat beberapa hal yang perlu direvisi yaitu: 1) beberapa instruksi memiliki kesalahan tata bahasa Bahasa Inggris sehingga perlu diperbaiki dan disesuaikan dengan bahasa formal, 2) pada topik “Analytic Geometry" seharusnya diberikan materi dukungan karena topik ini merupakan topik baru bagi mahasiswa. LMS diperbaiki sesuai dengan saran dan masukan dari validator.

LMS yang sudah diperbaiki kemudian diujikan kepada 5 mahasiswa yang mengambil mata kuliah geometri pada Semester Ganjil 2019/2020. Beberapa revisi dilakukan langsung 


\section{Histogram: Jurnal Pendidikan Matematika, 4 (2), 2020 - 509 \\ Deshinta Puspa Ayu Dwi Argaswari ${ }^{1}$}

sesuai dengan uji coba seperti mahasiswa kurang paham mengenai beberapa terminologies sehingga diperbaiki.

5. Tahap Implementasi

LMS Google Classroom diimplementasikan pada kelas Geometri semester genap tahun 2020. Mahasiswa calon guru bergabung dengan kelas, dan mengikuti perkuliahan secara blended learning artinya sebagian pembelajaran dilakukan secara tatap muka dan sebagian dilakukan secara daring. Setelah mahasiswa mengikuti perkuliahan geometri, mahasiswa diminta untuk memberikan saran terhadap pengunaan LMS Google Classroom pada perkuliahan Geometri. Selain itu mahasiswa juga diminta untuk mengisi kuesioner evaluasi penerapan LMS yang telah dikembangkan oleh MTebe \& Raisamo. Kuesioner telah divalidasi menggunakan konten validasi sejumlah 9 ahli dan dinyatakan valid. Kuesioner dinyatakan reliable dengan nilai Cronbach Alpa pada masing-masing aspek yaitu: kualitas mata kuliah 0.884, kualitas sistem 0.892, kualitas pengunaan LMS 0.846, kualitas kepuasan pengguna 0.880, dan kualitas kebermanfaatan 0.911. Penerapan LMS menunjukkan hasil berikut

Tabel 1. Indikator Aspek Kualitas Mata Kuliah

\begin{tabular}{lllc}
\hline No. & \multicolumn{1}{c}{ Pertanyaan } & Skor \\
\hline 1 & The courses have learning objectives that describe outcomes that are & 3.83 \\
& measurable (Mata kuliah memiliki tujuan pembelajaran yang & \\
& menggambarkan luaran yang terukur) & & \\
\hline 2 & The course content contributes to the achievement of the stated & 3.67 \\
& module/unit learning objectives (Konten mata kuliah mempengaruhi & \\
& pencapain dari tujuan pembelajaran) & 3.67 \\
\hline 3 & The course content in the LMS is accurate (Konten mata kuliah di LMS & \\
& akurat) & 3.67 \\
\hline 4 & The course content in the LMS is up-to-date (Konten mata kuliah di LMS & \\
& terbaru) & \\
\hline 5 & The courses have sufficient content required for me to complete learning & 3.67 \\
& process (Mata kuliah memiliki cukup konten yang saya perlukan untuk & \\
& menyelesaikan proses belajar) & 3.50 \\
\hline 6 & The content in the LMS is presented in ways appropriate to the learners & \\
& knowledge, skills and abilities (Konten di LMS disajikan dalam bentuk &
\end{tabular}


Histogram: Jurnal Pendidikan Matematika, 4 (2), 2020 - 510

Deshinta Puspa Ayu Dwi Argaswari ${ }^{1}$

\begin{tabular}{llll}
\hline No. & \multicolumn{1}{c}{ Pertanyaan } & Skor \\
\hline & yang sesuai dengan pengetahuan, ketrampilan, dan kemampuan & \\
pembelajar) & & \\
\hline 7 & $\begin{array}{l}\text { The content in the LMS presents educationally significant concepts, } \\
\text { models, and skills for the discipline (Konten di LMS menyajikan konsep, }\end{array}$ & \\
& $\begin{array}{l}\text { model, dan keterampilan yang secara pendidikan signifikan untuk disiplin } \\
\text { ilmu tersebut }\end{array}$ & 3.66
\end{tabular}

(Sumber: Data Primer, Tahun: 2020)

Pada indikator-indikator aspek kualitas mata kuliah dari nomor $1 \mathrm{~s} / \mathrm{d}$ nomor 7, dapat diamati bahwa rata-rata mahasiswa menyatakan kualitas mata kuliah adalah 3.66 dari 4.Hal ini berarti mahasiswa menyatakan kualitas mata kuliah sangat baik Skor tertinggi 3.83 terletak pada indikator nomor 1 yaitu mata kuliah memiliki tujuan pembelajaran yang menggambarkan luaran yang terukur. Skor terendah 3.50 terletak pada indikator 6 yaitu konten di LMS dipresentasikan sesuai dengan pengetahuan, keterampilan, dan kemampuan pembelajar.

Tabel 2. Indikator Aspek Kualitas Sistem

\begin{tabular}{llc}
\hline No. & \multicolumn{1}{c}{ Pertanyaan } & Skor \\
\hline 1 & The LMS is easy to use (LMS mudah digunakan) & 3.67 \\
\hline 2 & $\begin{array}{l}\text { The LMS is user friendly (LMS mudah dioperasikan karena pengguna } \\
\text { terbiasa) }\end{array}$ & 3.83 \\
\hline 3 & The LMS is easy to learn (LMS mudah dipelajari) & 3.67 \\
\hline & Rata-rata & 3.72
\end{tabular}

(Sumber: Data Primer, Tahun: 2020)

Kualitas sistem dari LMS juga mendapatkan respon yang baik dari mahasiswa. Hal ini ditunjukkan dari hasil survei, mahasiswa setuju bahwa LMS mudah digunakan dengan rata-rata skor 3.72 dari 4. Dengan demikian mahasiswa merasa bahwa kualitas sistem LMS sangat baik terutama LMS Google Classroom adalah "user friendly" dan karena terintegrasi dengan akun google hal tersebut menjadikan Google Classroom mudah digunakan mahasiswa. 
Histogram: Jurnal Pendidikan Matematika, 4 (2), 2020 - 511

Deshinta Puspa Ayu Dwi Argaswari ${ }^{1}$

Tabel 3. Indikator Aspek Kepuasan Pengguna

\begin{tabular}{llc}
\hline No. & \multicolumn{1}{c}{ Pertanyaan } & Skor \\
\hline 1 & I am pleased with the LMS (Saya merasa senang dengan menggunakan & 3.00 \\
& LMS) & \\
\hline 2 & I am very satisfied with the course content I access from LMS (Saya puas & 3.17 \\
& dengan konten mata kuliah yang saya akses di LMS) & \\
\hline 3 & $\begin{array}{l}\text { Overall, my interaction with LMS is very satisfying (Secara keseluruhan, } \\
\text { interaksi dengan LMS memuaskan) }\end{array}$ & 3.33 \\
\hline & \multicolumn{2}{c}{ Rata-rata } \\
\hline
\end{tabular}

(Sumber: Data Primer, Tahun: 2020)

Meskipun konten dan kualitas sistem dianggap sangat baik, kepuasan mahasiswa dalam menggunakan LMS tidak terlalu tinggi. Hal ini terlihat dari rata-rata indikator kualitas hanya sebesar 3.16 dari 4 . Siswa merasa cukup puas dalam mengakses konten mata kuliah geometri dari LMS Google Classroom. Hal ini dimungkinkan karena mode pembelajaran yang digunakan adalah Blended Learning yang kemudian menempatkan LMS sebagai media pendukung pembelajaran tatap muka.

Tabel 4. Indikator Aspek Penggunaan LMS

\begin{tabular}{llc}
\hline No. & \multicolumn{1}{c}{ Pertanyaan } & Skor \\
\hline 1 & I use LMS to help me to interact with my instructor (s) & 2.83 \\
& (Saya menggunakan LMS untuk membantu saya berinteraksi dengan & \\
& dosen) & 3.67 \\
\hline 2 & $\begin{array}{l}\text { I use LMS to access learning resources electronically } \\
\end{array}$ & \\
\hline 3 & (Saya menggunakan LMS untuk mengakses material) & 2.67
\end{tabular}

(Saya menggunakan LMS untuk berkomunikasi dan berbagi pengetahuan dengan teman)

$4 \quad$ I use LMS to accomplish and submit my assignments 4.00

(Saya menggunakan LMS untuk memenuhi dan mengumpulkan tugas)

\begin{tabular}{rr}
\hline Rata-rata & 3.29
\end{tabular}

(Sumber: Data Primer, Tahun: 2020)

Pada aspek penggunaan LMS, rata-rata mahasiswa memberikan persetujuan 3.29 terhadap penggunaan LMS dalam belajar geometri. Seluruh siswa sepakat bahwa LMS 


\section{Histogram: Jurnal Pendidikan Matematika, 4 (2), 2020 - 512 Deshinta Puspa Ayu Dwi Argaswari}

memudahkan siswa dalam mengumpulkan tugas. Hal ini dapat terlihat dari skor 4 yang diberikan siswa pada indikator nomor 4 dan mayoritas mahasiswa juga setuju bahwa LMS sangat digunakan untuk mengakses materi. Akan tetapi siswa merasa interaksi dengan dosen serta komunikasi dengan teman tidak terpenuhi dalam LMS ini. Terlihat dari skor indikator nomor 1 dan nomor 3 yang berada pada skor di bawah 3 .

Tabel 5. Indikator Aspek Kebermanfaatan

\begin{tabular}{lcc}
\hline No. & Pertanyaan & Skor \\
\hline 1 & Using LMS has helped me to accomplish my learning tasks more quickly & 3
\end{tabular}

(Dengan LMS, saya dapat menyelesaikan tugas-tugas saya lebih cepat)

2 Using LMS has made my learning activities become much easier than 3.17

before (Dengan LMS, aktivitas belajar saya menjadi lebih mudah dari sebelumnya)

$3 \quad$ My learning performance is enhanced since I started using LMS

(Performa belajar saya meningkat sejak menggunakan LMS)

$4 \quad$ Ifind the system useful in my studies

(Saya merasa sistem LMS berguna untuk saya belajar)

\begin{tabular}{ll}
\hline Rata-rata & 3
\end{tabular}

(Sumber: Data Primer, Tahun: 2020)

Mahasiswa juga menganggap kebermanfaatan LMS cukup baik. Rata-rata skor pada indikator kebermanfaatan adalah 3. Hal ini menunjukkan bahwa LMS yang digunakan dalam perkuliahan geometri dirasa cukup membantu mahasiswa dalam meningkatkan performa belajar mahasiswa. Hal ini juga dimungkinkan karena pengaruh dari sistem pembelajaran Blended Learning yang masih terlalu condong ke kegiatan tatap muka, akan tetapi belum cukup mengembangkan kegiatan pembelajaran daring yang bermanfaat bagi peningkatan belajar siswa. Meskipun hal ini tidak menyalahi definisi sistem pembelajaran blended learning seperti diutarakan Graham (2009) dan Bersin (2003) bahwa blended learning merupakan kombinasi antara kegiatan tatap muka dan daring. Akan tetapi perlu juga diperhatikan konteks dan karakteristik siswa (Zhang et al., 2004).

6. Evaluasi dan Revisi

Sebagai bentuk untuk memperoleh data tambahan, peneliti melakukan survei terbuka mengenai keefektivan LMS dalam pembelajaran geometri. Berikut adalah hasil analisis dari survei. Berdasarkan hasil survei dengan mahasiswa, mereka berpendapat 


\section{Histogram: Jurnal Pendidikan Matematika, 4 (2), 2020 - 513}

Deshinta Puspa Ayu Dwi Argaswari ${ }^{1}$

bahwa LMS Google Classroom yang disediakan untuk Mata Kuliah Geometri sangat berguna untuk mengakses material terutama video dan power point presentation slides. Material tersebut telah dibahas dalam kegiatan tatap muka, Sebagian dari video merupakan tambahan untuk belajar mandiri bagi mahasiswa yang masih kurang paham. Selain itu mahasiswa juga mudah bekerja sama dalam membuat PPT dengan teman satu kelompok melalui fitur koneksi Google Slides dan Google Classroom.

"Saya dapat dengan mudah mengakses video karena saya memerlukan video untuk belajar geometri. Saya juga menyukai pengumpulan ppt karena memudahkan saya dalam berkolaborasi dengan teman saat membuat tugas ppt" ("I can access video easily because I need video to learn geometry, and also I like the ppt submission. It makes me easier to collaborate with other doing the ppt")

Mereka juga menyatakan bahwa LMS yang disediakan mudah digunakan (easy to

use) karena materi tersaji dengan sederhana dan mudah terlihat.

"Saya rasa Google Classroom masih menjadi aplikasi yang paling mudah yang pernah saya gunakan terutama dalam belajar geometry" ("I think google classroom still be the easier app that I ever used for learning especially in geometry course")

Komentar ini diberikan oleh mahasiswa yang mengambil ulang mata kuliah Geometry, dimana sebelumnya mata kuliah Geometry dipelajari menggunakan LMS berbeda. Hal ini mendukung pendapat bahwa LMS Geometry tepat digunakan untuk belajar Geometry.

Kemudian mahasiswa menyatakan bahwa bagian LMS yang paling efektif adalah "reminder notifications" yang secara otomatis dikirimkan Google Classroom ke email mahasiswa setiap 24 jam sebelum tenggat waktu pengumpulan tugas yang tercantum di Google Classroom. Mahasiswa menyatakan bahwa mereka terbantu dengan adanya fitur ini dikarenakan mahasiswa menjadi mudah mengatur waktu pengerjaan tugas sebelum tenggang (manajemen tugas) dan email yang dikirimkan memiliki link yang bisa langsung terhubung ke tautan tugas yang harus dikerjakan. Selain itu, 40\% dari mahasiswa yang mengumpulkan survai juga menyatakan homepage Google Classroom sangat efektif dan efisien dalam penggunaannya. Homepage tertata rapi dalam tampilan yang sederhana sehingga memudahkan siswa ketika mencari materi atau mencari laman untuk mengumpulkan tugas.

"In Google Classroom we can choose what types of files do we want to submit our submission, we can even directly compose the assignments in google docs or spreadsheet or slides and once we submit it, we can no longer edit those features"( Di Google Classroom, kita bisa memilih tipe file apa yang ingin kita kumpulkan, 


\section{Histogram: Jurnal Pendidikan Matematika, 4 (2), 2020 - 514 \\ Deshinta Puspa Ayu Dwi Argaswari ${ }^{1}$}

kita bahkan bisa langsung mengerjakan tugas dengan klik google docs dan spreadsheet lalu klik tombol submit sehingga kita tidak bisa lagi edit tugas kita)

Terdapat hal menarik bahwa Google Classroom juga menyediakan berbagai pilihan jenis file untuk mengumpulkan tugas. Hal ini dirasa sangat bermanfaat oleh mahasiswa karena mereka dapat bebas menentukan mode pengerjaan tugasnya

Meskipun terdapat manfaat dan kemudahan dalam menggunakan LMS Google Classroom untuk belajar Geometri, masih terdapat beberapa bagian dari LMS yang perlu diperbaiki. Mahasiswa berpendapat bahwa bagian Discussion Forum kurang efektif digunakan. Hal ini dikarenakan topik diskusi online yang kurang digunakan karena sudah banyak diskusi tatap muka, kemudian topik yang digunakan juga kurang menarik. Mahasiswa memberi masukan agar Discussion Forum sebaiknya diisi dengan diskusi mengenai topik baru yang dipelajari dari sesi tatap muka atau diskusi mengenai korelasi antara topik bahasan dengan keadaan nyata disekitar mahasiswa. Kekurangan ini sejalan dengan hasil survei mahasiswa pada bahasan sebelumnya, dimana mahasiswa kurang merasa bisa berinteraksi dengan teman maupun dosen dikarenakan miniminnya penggunaan forum diskusi. Oleh karena itu, LMS Google Classroom untuk mata kuliah geometri perlu disempurnakan pada bagian forum diskusi

Selain itu, mahasiswa berpendapat sebaiknya di Google Classroom disediakan chat box, sehingga mahasiswa bisa saling berinteraksi dengan lebih cepat. Akan tetapi hal ini tidak dapat direalisasikan karena sampai pada saat ini Google Classroom belum menyediakan fitur tersebut.

\section{B. Pembahasan}

Pengembangan LMS Google Classroom mengikuti tahap pengembangan dari Plomp telah dilakukan sehingga menghasilkan LMS Google Classroom untuk belajar mata kuliah geometri. Hasil pengembangan LMS memuat berbagai aspek seperti 1) laman komunikasi yang digunakan untuk pengumuman informasi, 2) pengembangan konten yang berisi material pembelajaran baik berupa link ataupun file, 3) assessmen formatif dan sumatif yang berisi laman untuk tes dan pengumpulan tugas, 4) manajemen kelas dan pengguna. Merujuk pada Coates dalam penelitiannya dijelaskan bahwa meskipun standar LMS belum diatur secara baku, paling tidak LMS seharusnya memiliki keempat aspek tersebut sehingga bisa disebut LMS sudah terstandar secara internasional (Coates et al., 2005). 


\section{Histogram: Jurnal Pendidikan Matematika, 4 (2), 2020 - 515 \\ Deshinta Puspa Ayu Dwi Argaswari ${ }^{1}$}

Hasil penerapan LMS menunjukkan mahasiswa setuju bahwa kualitas konten geometri dan kualitas sistem LMS Google Classroom sangat baik hal ini ditunjukkan dengan rata-rata tinggi pada kedua aspek tersebut yaitu 3,67 dan 3,72 secara berurutan. Hasil ini juga bisa menunjukkan bahwa pengajaran sudah sesuai dengan standar kualitas pengajaran dikarenakan poin pertanyaan pada aspek ini diambil dari QMRS (2012). Mahasiswa merasa terbantu dengan ketersediaan materi di LMS dan kemudian video yang diberikan dapat membantu mahasiswa memahami materi lebih baik. Selain itu, tersedianya semua materi dan silabus di LMS membuat pembelajaran menjadi transparan, mahasiswa calon guru mengetahui tujuan pembelajaran yang menggambarkan luaran yang terukur. Hal ini penting untuk mahasiswa calon guru karena mereka nantinya akan menjadi guru sehingga pengalaman pembelajaran yang transparan akan memberikan inspirasi bagi calon guru kedepannya. Selanjutnya mahasiswa setuju bahwa penggunaan LMS dalam pembelajaran geometri juga baik yaitu sebesar 3.29 dari 4. Hal ini didukung dari komentar mahasiswa yang menyatakan bahwa materi dapat dengan mudah diakses dan mahasiswa juga diberi kemudahan dalam mengumpulkan tugas terutama dengan adanya fitur pengingat tugas yang dikirimkan lewat email setiap 24 jam menjelang tenggat pengumpulan tugas. Akan tetapi mahasiswa menyatakan bahwa interaksi antar dosen dan teman tidak terjalin dengan baik di LMS. Hal ini dapat dilihat dari hasil survei dimana mahasiswa menyatakan sebaiknya forum diskusi di LMS dibuat lebih menarik dengan membahas pemahaman baru di kelas tatap muka atau menghubungkan pokok bahasan geometri dengan kehidupan nyata. Selanjutnya, mahasiswa cukup setuju bahwa mereka merasa puas dalam menggunakan LMS yaitu sebesar 3.19 dari 4. Terakhir, mahasiswa merasa LMS cukup memberikan kebermanfaatan untuk mahasiswa belajar.

\section{KESIMPULAN DAN SARAN}

\section{A. Kesimpulan}

Kualitas LMS Google Classroom Mata Kuliah Geometri dievaluasi menggunakan Standar Evaluasi Mtebe \& Raisamo. Hasil dari survei menunjukkan bahwa kelima aspek yang diteliti mendapatkan respon baik dengan detil sebagai berikut: 1) aspek mata kuliah skor 3,66, 2) aspek kualitas sistem skor 3,72, 3) aspek kepuasan pengguna skor 3,16, 4) aspek pengunaan LMS skor 3,29, dan 5) aspek kebermanfaatan skor 3. Dapat terlihat bahwa kelima aspek yang dievaluasi memperoleh skor diatas 3 dari 4. Oleh karena itu dapat 


\section{Histogram: Jurnal Pendidikan Matematika, 4 (2), 2020 - 516 Deshinta Puspa Ayu Dwi Argaswari ${ }^{1}$}

disimpulkan bahwa LMS Google Classroom untuk mata kuliah Geometri memiliki kualitas baik.

Berdasarkan hasil pada penelitian dan pengembangan ini juga diperoleh kesimpulan bahwa pengunaan LMS Google Classroom untuk mata kuliah Geometri memiliki kelebihan pada kualitas mata kuliah dan kualitas sistem. Kualitas mata kuliah baik, sehingga pembelajaran menjadi lebih transparan dengan tersedianya materi dan silabus di LMS Google Classroom, dengan contoh seperti ini mahasiswa calon guru merasa dapat mengambil inspirasi untuk mereka di masa depan. Selain itu, mahasiswa merasa dengan tersedianya semua materi di LMS, memudahkan mahasiswa untuk belajar geometri. Video-video yang diberikan membantu siswa belajar di luar kelas dengan lebih baik. Selain itu mahasiswa terbantu dengan pengingat notifikasi email yang diberikan Google Classroom setiap 24 jam sebelum tenggat waktu pengumpulan tugas atau tes, tampilan LMS yang sederhana dan mudah digunakan, selain itu koneksi Google Classroom dengan Google Docs, Google Spreadsheet dan Google Slides memberikan kemudahan bagi mahasiswa untuk merancang tugas. Akan tetapi terdapat hal yang berlum dimaksimalkan dalam LMS yang dikembangkan yaitu masih terbatasnya topik diskusi pada forum diskusi.

\section{B. Saran}

Berdasarkan kesimpulan hasil penelitian dan pengembangan, LMS Google Classroom untuk mata kuliah Geometri telah berhasil dikembangkan akan tetapi terdapat beberapa hal yang perlu diperbaiki untuk pengembangan kedepannya yaitu berkenaan dengan fungsi interaksi dan kebermanfaatan. Hal ini dikarenakan LMS yang dikembangkan bertujuan untuk kegiatan belajar blended learning sehingga fungsi-fungsi tersebut telah terjadi di dalam ruang kelas. Akan tetapi, jika LMS yang akan dikembangkan digunakan untuk pembelajaran daring secara keseluruhan maka fungsi-fungsi tersebut perlu dimaksimalkan.

\section{DAFTAR PUSTAKA}

Afrianti, W. E. (2018). Penerapan Google Classroom Dalam Pembelajaran Akuntansi ( Studi Pada Program Studi Akuntansi Universitas Islam Indonesia) SKRIPSI Oleh : Nama: Wahyuni Eka Afrianti Fakultas Ekonomi Universitas Islam Indonesia Yogyakarta. 1-122. https://dspace.uii.ac.id/handle/123456789/6173

Argaswari, D. P. A. . (2018). Integrasi Sejarah Matematika untuk Meningkatkan Atensi Siswa. Indonesian Journal of Mathematics Education, l(1), 59. 


\section{Histogram: Jurnal Pendidikan Matematika, 4 (2), 2020 - 517 \\ Deshinta Puspa Ayu Dwi Argaswari ${ }^{1}$}

https://doi.org/10.31002/ijome.v1i1.950

Bersin. (2003). Blended Learning: What Works?: An Industry Study of the Strategy, Implementation, and Impact of Blended Learning: Bersin \& Associates. Open Journal of Social Sciences. http://www.waset.org/journals/waset/v63/v63-94.pdf

Coates, H., James, R., \& Baldwin, G. (2005). A critical examination of the effects of learning management systems on university teaching and learning. Tertiary Education and Management, 11(1), 19-36. https://doi.org/10.1080/13583883.2005.9967137

Darmawan, D. (2012). Inovasi Pendidikan.

DeLone, W. H., \& McLean, E. R. (2003). The DeLone and McLean model of information systems success: A ten-year update. Journal of Management Information Systems, 19(4), 9-30. https://doi.org/10.1080/07421222.2003.11045748

Driscoll, M. (2002). Blended learning: Let's get beyond the hype. E-Learning, 54. http://www-07.ibm.com/services/pdf/blended learning.pdf

Graham, C. (2009). The Handbook of Blended Learning. In John Wiley \& Sons. https://doi.org/10.4018/978-1-4666-8632-8.ch068

Heryaningsih, N. Y., \& Usodo, B. (2015). Pengembangan Model Intuition Based Learning ( Ibl) Dengan Scientific Approach Untuk Meningkatkan Hasil Belajar Matematika. 3(9), 959-969.

Lin, H. F. (2007). Measuring online learning systems success: Applying the updated DeLone and McLean model. Cyberpsychology and Behavior, 10(6), 817-820. https://doi.org/10.1089/cpb.2007.9948

Mayes, T. (2004). Review of E-learning Theories, Frameworks and Models. In JISC Elearning Models Study Report (Vol. 02, Issue 04). https://doi.org/10.4236/oalib.1101424

Mtebe, J. S., \& Raisamo, R. (2014). A model for assessing learning management system success in higher education in sub-saharan Countries. Electronic Journal of Information Systems in Developing Countries, 61(1), 1-17. https://doi.org/10.1002/j.1681-4835.2014.tb00436.x

Nasrulloh, I., \& Ismail, A. (2018). Analisis Kebutuhan Pembelajaran Berbasis Ict. Jurnal Petik, 3(1), 28. https://doi.org/10.31980/jpetik.v3i1.355

QMRS. (2012). Quality Matters Rubric Standards 2011-2013 edition. https://doi.org/10.21608/jsre.2018.8404

Retnani, E. (2011). Learning Management System (LMS) sebagai Bahan Pembelajaran Untuk Meningkatkan Hasil Belajar Kognitif Siswa. https://doi.org/10.1017/CBO9781107415324.004

Sukmadinata, N. S. (2005). Metode Penelitian Pendidikan.

Ventayen, R. J. M., Estira, K. L. A., Guzman, M. J. De, Cabaluna, C. M., \& Espinosa, N. N. (2018). Usability Evaluation of Google Classroom: Basis for the Adaptation of GSuite E-Learning Platform Software Management View project Data Analysis View project. Asia Pacific Journal of Education, Arts and Sciences, 5(1), 47-51.

Zhang, D., Zhao, J. L., Zhou, L., \& Nunamaker, J. F. (2004). Can e-learning replace classroom learning? Communications of the ACM, 47(5), 75-79. https://doi.org/10.1145/986213.986216 